\section{Structure of an Ebf1:DNA complex reveals unusual DNA recognition and structural homology with Rel proteins}

Nora Treiber, ${ }^{1,3}$ Thomas Treiber, ${ }^{1,3}$ Georg Zocher, ${ }^{2}$ and Rudolf Grosschedl ${ }^{1,4}$

${ }^{1}$ Department of Cellular and Molecular Immunology, Max Planck Institute of Immunobiology, 79108 Freiburg, Germany; ${ }^{2}$ Interfaculty Institute for Biochemistry, University of Tübingen, 72076 Tübingen, Germany

Early B-cell factor 1 (Ebf1) is a key transcriptional determinant of B-lymphocyte differentiation whose DNAbinding domain has no sequence similarity to other transcription factor families. Here we report the crystal structure of an Ebf1 dimer bound to its palindromic recognition site. The DNA-binding domain adopts a pseudoimmunoglobulin-like fold with novel topology, but is structurally similar to the Rel homology domains of NFAT and NF-кB. Ebf1 contacts the DNA with two loop-based modules and a unique $\mathrm{Zn}$ coordination motif whereby each Ebf1 monomer interacts with both palindromic half-sites. This unusual mode of DNA recognition generates an extended contact area that may be crucial for the function of Ebf1 in chromatin.

Supplemental material is available at http://www.genesdev.org.

Received August 2, 2010; revised version accepted August 23,2010

Early B-cell factor 1 (Ebf1) is the best-studied member of the EBF family (also known as the CO/E family) of transcription factors, which is common to all metazoans (Liberg et al. 2002). The EBF family includes four members (Ebf1-4) in mammals, one member (knot/collier) in Drosophila (Krzemien et al. 2007), and one member (unc3) in Caenorhabditis elegans (Kim et al. 2005). EBF family proteins consist of an N-terminal DNA-binding domain (DBD) of $\sim 225$ amino acids, a transcription factor immunoglobulin (TIG/IPT) domain, and a helix-loop-helix (HLH) domain, followed by a C-terminal transactivation domain, which is predicted to be unstructured (Hagman et al. 1995). They form stable dimers via the HLH domain (Hagman et al. 1995) and bind to the palindromic consensus motif 5'-TCCCNNGGGA-3' (Travis et al. 1993; Treiber et al. 2010).

[Keywords: Ebf1; NFAT; NF-кB; Rel homology domain; IPT/TIG domain; HLH domain; protein-DNA interaction]

${ }^{3}$ These authors contributed equally to this work.

${ }^{4}$ Corresponding author.

E-MAIL grossched1@immunbio.mpg.de; FAX 49-761-5108-799.

Article published online ahead of print. Article and publication date are online at http://www.genesdev.org/cgi/doi/10.1101/gad.1976610. Freely available online through the Genes \& Development Open Access option.
All EBF proteins characterized to date play important roles in developmental processes, including cell fate decisions, cell differentiation, and cell migration (Liberg et al. 2002). Ebf1 is essential for the differentiation of B lymphocytes, as a loss of gene activity leads to a complete block at the pre-pro-B-cell stage (Lin and Grosschedl 1995). Conversely, forced expression of Ebfl in hematopoietic stem cells or multilineage progenitors leads to enhanced formation of B lymphocytes at the expense of other lineages, demonstrating the instructive capacity of Ebf1 (Zhang et al. 2003; Medina et al. 2004; Pongubala et al. 2008). In addition, Ebf1 regulates the differentiation of adipocytes (Jimenez et al. 2007) and sensory neurons (Wang et al. 1997; Garel et al. 1999). Finally, a role for EBF proteins as tumor suppressors is beginning to emerge (Liao 2009).

Genome-wide analysis of Ebf1 occupancy by chromatin immunoprecipitation (ChIP) and deep sequencing (ChIPseq) in pro-B cells, coupled with expression analysis in lossand gain-of-function studies, identified a multitude of targets that are either activated, repressed, or poised for expression by Ebf1 (Lin et al. 2010; Treiber et al. 2010). Among the activated genes directly regulated by Ebf1 are several transcription factors and many signaling molecules that are necessary to establish the antigen receptor signaling network (Treiber et al. 2010). Moreover, transcriptionindependent poising of specific gene targets by Ebfl was found to correlate with the appearance of histone H3K4me2 modifications (Treiber et al. 2010). This function of Ebf1, together with its proposed role in initiating DNA demethylation (Maier et al. 2004), suggests that Ebf1 may act as a "pioneer factor" in lineage-specific gene activation. Despite the substantial insights into the functional roles of Ebf1, very little is known about the molecular basis for DNA recognition by Ebf1.

\section{Results and Discussion}

\section{Structure of Ebf1 bound to DNA}

To gain insight into the mechanism of DNA recognition by EBF proteins, we recombinantly expressed the DBD of murine Ebf1 (amino acids 26-240) and cocrystallized it with a DNA duplex containing the Ebf1 consensus binding site. The structure, determined at $2.4 \AA$, shows two DBD molecules bound as a symmetric dimer to the palindromic DNA duplex (Fig. 1A), and an additional Ebf1 monomer not bound to DNA (Supplemental Fig. S1). The DBD folds into a $\beta$ sandwich, in which a four-stranded $\beta$ sheet (consisting of strands $A, B, G$, and F) packs against a five-stranded sheet formed by strands C, D, E, H, and I. The $\mathrm{N}$ terminus forms an $\alpha$ helix (helix 1) and packs against the bottom of the $\beta$ structure. The apical part of the domain is formed by three additional short $\beta$ strands (X, Y, and Z) and extensive loops that constitute the DNAbinding surface. The unusual $\mathrm{Zn}$ knuckle, which does not fit into any described class of zinc fingers (Schwabe and Klug 1994), is formed by a loop and three short helices (helices 2, 3, and 4) that are stabilized by a centrally coordinated zinc ion (Supplemental Fig. S2). The Zn knuckle protrudes from one side of the domain and also participates in DNA recognition. The two protein monomers contact each other at a small interface of $240 \AA^{2}$, formed by a loop and a $3_{10}$ helix. The C-terminal loops of 

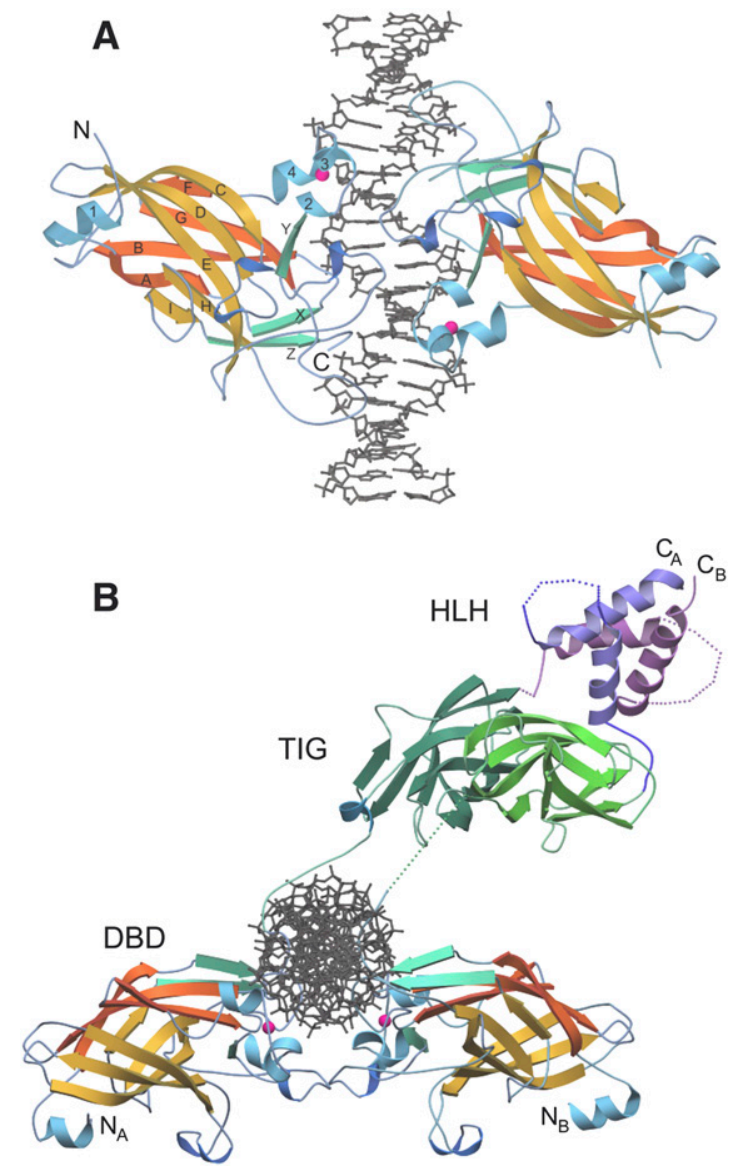

Figure 1. Crystal structure of Ebf1 bound to DNA. $(A)$ Structure model of a dimer of Ebf1 DBDs bound to DNA. $\beta$ Strands of the $\beta$-sandwich assembly are shaded in yellow and orange and are labeled A-I. Additional strands are colored green and are labeled $\mathrm{X}-\mathrm{Z}$. Helices are shown in blue and are numbered. Zinc ions are represented by pink spheres. (B) Structure model of dimeric Ebf1 $1^{26-422}$ bound to DNA. DBDs are shaded as in A, TIG domains are shown in light and dark green, and HLH domains are blue and purple. Unstructured loops and linkers are indicated as dashed lines.

the DBDs run through the major groove, leaving the domain opposite of the dimerization interface. A detailed assignment of secondary structure elements within the DBD is shown in Supplemental Figure S3. A second crystal form with only one Ebf1:DNA complex in the asymmetric unit yielded an identical model at $3.0 \AA$ resolution (data not shown).

Purification and crystallization of a complex consisting of a longer Ebf1 protein fragment (amino acids 26-422) and a cognate oligonucleotide provided additional structural information about the TIG domain and the HLH dimerization domain at $2.8 \AA$ resolution (Fig. 1B). The structure models for the DNA-bound DBDs from the three crystal forms at different $\mathrm{pHs}$ are essentially identical, with a $\mathrm{C}_{\alpha}$ RMSD (root-mean-square deviation) between $0.45 \AA$ and $0.62 \AA$ for the individual chains, corroborating the presented structure. The $\mathrm{C}$ termini of the DBDs are connected to the TIG domains by a linker, which is visible in only one of the monomers. Due to the length $(\sim 25 \AA)$ and flexibility of the linker, the orientation of the TIG domains relative to the DBDs is probably determined by crystal packing. As predicted from sequence comparison, the TIG domains adopt an Ig-like fold. Although they form a considerable dimer interface $\left(490 \AA^{2}\right)$, the major part of the contact area is contributed to by the HLH domains, which are necessary for dimerization in the absence of DNA (Hagman et al. 1995). In the structure, the electron density for the HLH domain was only weakly defined. However, four helices that form a helix bundle reminiscent of dimerized HLH domains, such as those found in MyoD (Ma et al. 1994), were discernable in one of the two Ebf1 dimers of the asymmetric unit. In all vertebrate EBF proteins, the second helix of the HLH motif is duplicated, which has been interpreted to suggest that the dimerization domains of these factors are considerably divergent from canonical HLH domains. No additional electron density for the duplicated third helix could be detected, arguing against a compact inclusion of this helix in the HLH domain.

Within the EBF family of transcription factors, the domain architecture of the individual members is strictly conserved (Liberg et al. 2002). Moreover, the three structurally investigated domains exhibit high sequence conservation, making it unlikely that major deviations in structure will be found in other EBF family members.

\section{Ebf1 is structurally related to Rel family proteins}

To explore the structural relationship of Ebf1 with other proteins, we searched for structures with homology with the TIG domain and the DBD using DALI (Holm et al. 2008). As predicted by sequence comparison, the TIG domain is similar to the homologous domains of NFAT and NF- $\mathrm{BB}$ that constitute the C-terminal half of the Rel homology domain (RHD) (Supplemental Fig. S4). For the DBD, modest structural similarities to the Ig-fold DBDs of STAT, p53, and the N-terminal half of the RHD of the NF-кB and NFAT families were found (Supplemental Table S3). For both domains, NFAT1 (Giffin et al. 2003) shows the highest structural similarity to Ebfl. Moreover, the overall arrangement of the TIG-binding domains and DBDs in the DNA-bound dimers is similar, raising the intriguing possibility that the EBF proteins structurally represent a branch of the Rel superfamily (Fig. 2A).

The TIG domains mediate dimerization in all Rel family members. With the exception of an asymmetric NFAT1 dimer (Giffin et al. 2003), the interfaces in the reported structures are symmetric and consist of a hydrophobic patch surrounded by residues forming $\mathrm{H}$ bonds and salt bridges (Ghosh et al. 1995; Muller et al. 1995 ; Stroud et al. 2002). The contact areas range from $650 \AA^{2}$ to $740 \AA^{2}$. The TIG domains of Ebfl dimerize at the homologous surface (Supplemental Fig. S4), but the interface is markedly smaller $\left(490 \AA^{2}\right)$ and slightly tilted compared with the Rel proteins. In addition, it lacks important residues, especially most of those mediating the polar interactions (Supplemental Fig. S4). These differences with Rel family members probably necessitate the presence of the HLH domain for stable dimerization. The TIG domain apparently represents a genetic module that has been evolutionarily adapted by the Rel and EBF families. However, its main functions of dimerization in the Rel family and dimerization and DNA binding in NF- $\kappa \mathrm{B}$ are not obvious in EBF proteins, and the role of this domain still remains elusive.

Both the DBD of Ebfl and the N-terminal part of the RHD use a $\beta$ sandwich as a scaffold for the DNA-binding loops. For Ebf1 and NFAT1, this central structure can be 

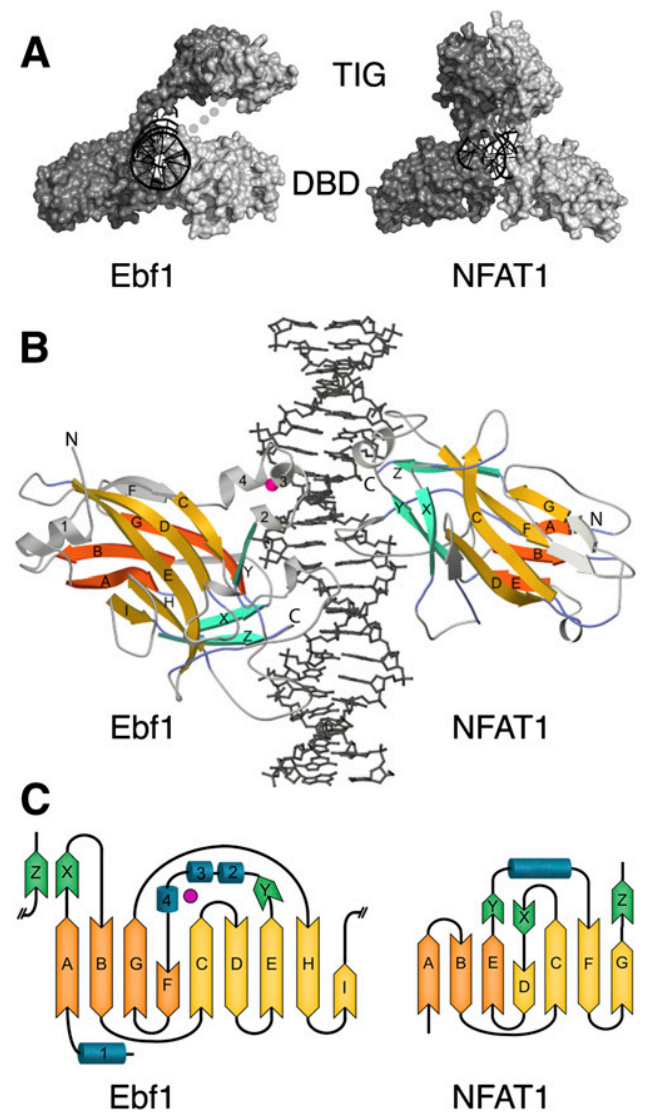

Figure 2. The Ebf1 DBD resembles an RHD with a novel pseudo-Iglike fold. (A) Surface representations of Ebf1 and NFAT1 (PDB: 1P7H) bound to their cognate DNA-binding sites. $(B)$ Structure model of an Ebf1 DBD and an NFAT1 DBD shown after superposition of an NFAT1 monomer onto the second Ebfl subunit of a DNA-bound dimer. The DNA of the superposed structures assumes an equivalent position. Regions that overlay with a $\mathrm{C} \alpha$ deviation below $3 \mathrm{~A}$ are colored according to Figure $1 \mathrm{~A}$; structurally divergent regions are shown in gray. $(C)$ Topology plots of the DBDs of Ebf1 and NFAT1.

superposed with a C $\alpha$ RMSD of $2.14 \AA$ (98 aligned residues) (Fig. 2B). However, no significant sequence similarity is detected in the structurally equivalent regions (Supplemental Fig. S5), showing that the DBD of EBF proteins represents an evolutionarily independent domain. Moreover, the $\beta$ strands are arranged in a different topology. While NFAT1 and all other analyzed Ig-like DBDs (see Supplemental Table S3 for a complete list and references) adopt a canonical "Greek-key" Ig-like fold, Ebfl shows an unprecedented pseudo-Ig-like fold in which the $\beta$ strands are connected in a unique manner (Fig. 2C). The use of a different topological arrangement of the $\beta$ sheets in Ebf1 and Ig-like DBDs represents an interesting example of convergent evolution.

\section{DNA binding by Ebf1}

Ebf1 contacts the cocrystallized DNA duplex over a region of 18 base pairs (bp), which is consistent with the size of Ebf1 footprints in DNase I protection experiments (Hagman et al. 1991). The major and minor grooves of the DNA are contacted with three distinct modules (Fig. 3A). A central moiety that comprises the loop between $\beta$ strands $\mathrm{X}$ and $\mathrm{B}$ and the $\mathrm{C}$-terminal loop recognizes bases of one half-site of the palindromic binding site, whereas the $\mathrm{Zn}$ knuckle contacts the other half-site in the minor groove. Unlike other dimeric transcription factors in which each monomer recognizes only one half-site of the recognition sequence, the Ebf1 dimer forms a unique symmetric clamp over the entire binding site in which each monomer contacts both half-sites. This assembly explains the strict requirement for a 2-nucleotide (nt) spacer between the half-sites, as has been noticed in mutation analyses (Travis et al. 1993). In addition, the large loop between strands $\mathrm{G}$ and $\mathrm{H}$ (termed the GH loop) protrudes into the minor groove outside of the conserved recognition motif (Fig. 3A). The importance of this contact is corroborated by a methylation interference assay that showed reduced binding of Ebf1 to DNA methylated in these positions (Hagman et al. 1991). Three residues in the GH loop (N197, G203, and N204) form H bonds to the DNA backbone and bases (Fig. 3B). While the side chain of N197 binds to two phosphate groups of the DNA backbone, the peptide nitrogen of G203 and the side chain of N204 form $\mathrm{H}$ bonds to bases T18 and A20, respectively. However, the contacted positions $/ \mathrm{O} 2$ in $\mathrm{T} 18$, and N3 in A20) are occupied by a hydrogen acceptor, regardless of the type of base. Thus, no sequence specificity is generated by these protein:base contacts. The major contribution to specific DNA recognition is provided by the central module, which fills the major groove over one half-site of the palindrome (Fig. 3C) and contacts the nucleotides that had been found to define the Ebf recognition motif (Travis et al. 1993; Treiber et al. 2010). It comprises the R63-F67 loop and the C-terminal loop (amino acids 234-239), which is held in position by $\mathrm{H} 235$. Four amino acids from this module form hydrogen bonds with the invariant bases of the recognition site: R63 reaches deep into the groove and contacts nucleotides C9 and G13. From the C-terminal loop, the backbone carbonyl of N236 and the side chains of S238 and K239 form hydrogen bonds with DNA bases contacting C8, G14, and G15.

The Zn knuckle (amino acids 157-175), which contacts the half-site from the other side in the minor groove, forms extensive hydrogen bonds with the sugar-phosphate backbone at the flanks of the groove. R163 and N172, which have been shown previously to be involved in DNA binding (Hagman et al. 1995), point into the groove. R163 binds the base and ribose of C8, whereas N172 forms a hydrogen bond with the ribose of C9 and, in addition, fixes the guanidino group of R163 in place by another hydrogen bond (Fig. 3D). The Zn knuckle has several unusual features that, taken together, result in a unique structural motif (Supplemental Fig. S2). With a core of just 14 residues, it is one of the shortest stretches of amino acids capable of forming an independent structural unit. In contrast to other zinc fingers (Schwabe and Klug 1994), most of its secondary structure does not consist of $\beta$ sheets or loops, but very short $\alpha$ helices. Furthermore, DNA binding occurs in the minor groove, and is mediated by R163 in apical helix 3 and by residues in helix 4, which resembles a very short recognition helix.

\section{Functional validation of the Ebf1:DNA contacts}

The protein:base interactions schematically summarized in Figure $3 \mathrm{E}$ were validated in an electrophoretic mobility shift assay using a perfect palindromic Ebf1-binding site 

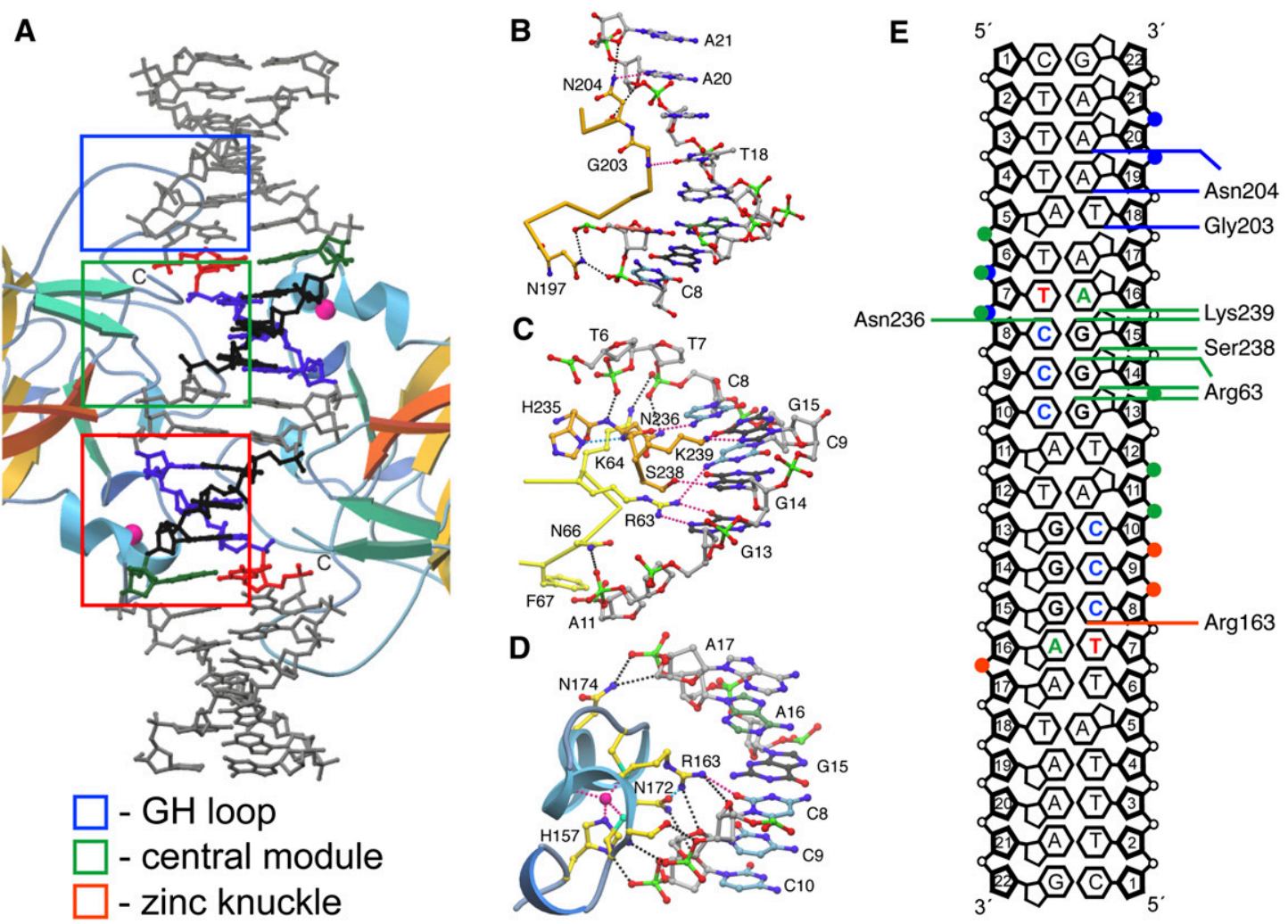

Figure 3. DNA-binding interface of Ebf1. (A) Structure model of a DNA strand contacted by an Ebf1 dimer. The conserved nucleotides of the binding motif are colored (A [green], T [red], C [blue],G [black]), and other nucleotides are gray. The three DNA interaction modules of one monomer are highlighted (GH loop [blue], major groove module [green], Zn knuckle [red]). (B-D) Detailed view of DNA contacts made by the GH loop $(B)$, the major groove module $(C)$, and the Zn knuckle $(D)$. (E) Schematic summary of the DNA contacts made by one Ebf1 monomer. Hydrogen bonds to bases are indicated by lines, and backbone phosphates contacted by $\mathrm{H}$ bonds are marked by colored spheres. The contact modules are color-coded as in $A$. Stereoscopic versions of $B-D$ are shown in Supplemental Figure S6.

(Fig. 4A). H235 (which structurally supports the C-terminal loop) and the DNA-contacting residues R63 and R163 are essential for DNA binding. Mutation of G203 to glutamate strongly reduces Ebf1:DNA complex formation by preventing binding of the GH loop in the minor groove. Mutation of other residues to alanine also reduces DNA binding (Fig. 4A). Using the natural Ebf1-binding site of the $m b-1$ (CD79a) promoter (Hagman et al. 1991), which consists of an imperfect palindrome, all mutations except N204A strongly reduce DNA binding (Fig. 4B). Mutation of both K146 and N147, which are involved in dimerization of the DBD (Supplemental Fig. S7), has only a modest effect on the binding of Ebf1 to the perfect palindrome, but severely affects the binding to the $m b-1$ site. This finding argues for a role of this contact in the cooperative binding of both DBDs to imperfect recognition sites (Hagman et al. 1995). In a model for such a cooperative mode of binding, the perfect half-site would first recruit one Ebf1-DBD, and the second DBD would then bind to a composite contact platform formed by the imperfect DNA half-site and the dimer surface of the first DBD. Natural Ebfl-binding motifs, including the single site found in the promoter of Cd79a (mb-1), frequently contain one perfect and one imperfect half-site (Hagman et al. 1991), suggesting that the dimerization of Ebf1-DBD is, at least in some promoters, functionally relevant.

In addition, we tested selected mutants of Ebf1 for their ability to activate the Ebf1 target gene Igll1 (lambda5) in the hematopoietic progenitor cell line $\mathrm{BaF} / 3$ (Fig. 4C). With the exception of K239A, all mutations tested markedly impaired the up-regulation of Igll1 by Ebf1, most likely reflecting a reduced binding to the regulatory elements in the Igll1 promoter. However, the effect of the K146A N147A double mutation is modest, which is probably due to the presence of multiple Ebfl-binding sites in this promoter. Taken together, the mutational and functional analysis confirms the role of specific residues in mediating protein-DNA interactions.

After completion of this study, the Structural Genomics Consortium (SGC) reported the structures of individual domains of Ebf1 and Ebf3 in the absence of DNA (Siponen et al. 2010). The domain structures presented by the SGC are essentially identical to the folds found in the DNAbound dimers of our study. However, the SGC researchers did not recognize the novel topology of the DBD. In addition, they tried to computationally model the binding of Ebf 1 to its recognition site. The resulting model shows two Ebf1-DBDs that form an incorrectly oriented dimer. The predicted binding to the DNA is highly asymmetric and involves contacts of the Zn knuckle to DNA bases in the major groove, none of which reflects the actual binding mechanism. Finally, Siponen et al. (2010) claim that the first two helices of the HLH domain form a new helical bundle-like fold, which is not supported by the obvious similarity with the dimerizing regions of other HLH factors (i.e., MyoD; RMSD $2.7 \AA$ for 40 amino acids). 

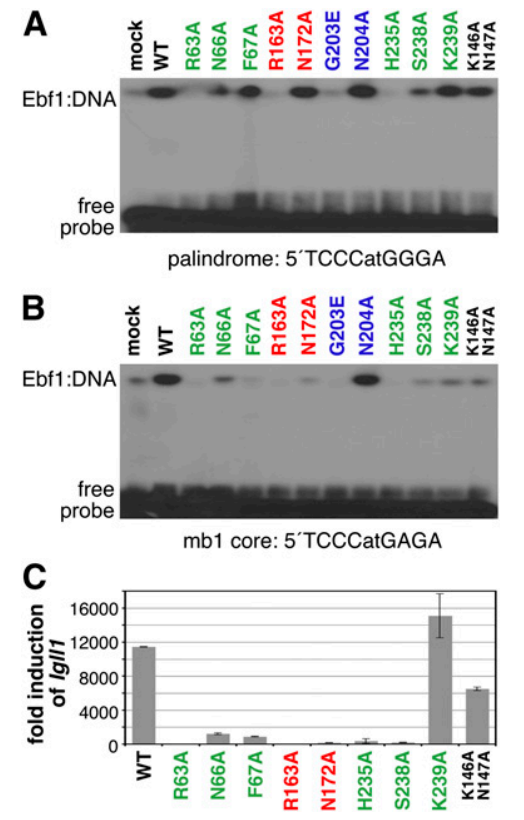

Figure 4. Mutation analysis of the Ebfl:DNA interaction. $(A, B)$ Electrophoretic mobility shift assays using in vitro translated wildtype (amino acids 26-422) and mutant Ebf1 proteins with ${ }^{32} \mathrm{P}$-labeled oligonucleotides containing a perfect Ebf1-binding site $(A)$ or the Ebf1-binding site of the $m b-1$ promoter containing one imperfect half-site $(B)$. Positions of the free oligonucleotide and the Ebf1:DNA complex are indicated. The color code corresponds to that of Figure 3. (C) Quantitative RT-PCR analysis of $I g l l 1$ expression in BAF/3 cells infected with a control or Ebf1-expressing retrovirus. Cycle numbers were normalized to the expression of the housekeeping gene Tpi, and are shown as fold expression over the control virusinfected samples. Error bars represent standard deviations of duplicate experiments. Expression controls for the experiments are shown in Supplemental Figure S8.

However, the duplicated HLH, which is not visible in our structure, is weakly defined in one monomer of the Ebf3 TIG/HLH structure, and is found to interact with the HLH of the other monomer, suggesting that it may contribute to dimerization.

\section{Implications for the function of Ebf1 as a 'pioneer' factor}

Ebf1 has been proposed to act as a "pioneer" transcription factor in the early steps of activation of developmentally regulated genes (Maier et al. 2004; Treiber et al. 2010). The overall contact surface of the Ebfl DBD dimer with the DNA duplex is nearly $3000 \AA^{2}$, and thus represents one of the largest interfaces reported for transcription factors. The dimerization contacts of the TIG and HLH domains on one side of the DNA and the interface between the DBDs on the opposite side lead to a complete encirclement of the DNA by Ebf1, similar to other members of the NFAT and NF-kB families (Ghosh et al. 1995; Muller et al. 1995; Stroud et al. 2002). However, unlike the topologically constrained TIG domain of NF- $\mathrm{kB}$, which mediates dimerization and DNA contacts, the Ebf1 TIG domain, which is attached via a flexible linker, contributes only to dimerization and may necessitate compensatory DNA contacts via the $\mathrm{Zn}$ knuckle in the Ebf1 DBD. The encirclement of DNA, which allows c-Rel homodimers to bind a consensus NF- $\mathrm{kB}$ site with an affinity of $0.5 \mathrm{nM}$ (Sanjabi et al. 2005), most likely does not allow Ebf1 to bind its recognition motif in the context of nucleosomewrapped DNA. In the presence of nucleosome-remodeling activity, however, the extensive DNA contacts may allow EBF proteins to stably occupy their binding sites and form barriers for nucleosome sliding. Consistent with this view, our recent ChIP-seq and ChIP analysis showed that Ebf1 needs a preconditioned or permissive chromatin context for binding to tissue-specific genes (Treiber et al. 2010). Thus, the multiple DNA recognition and dimerization modules of the Ebf1-DNA complex may stabilize the complex in chromatin and allow for the "pioneer" function of Ebfl in lineage-specific gene regulation.

\section{Materials and methods}

\section{Crystallization and structure solution}

Ebf $1^{26-240}(\mathrm{DBD})$ and Ebf1 ${ }^{26-422}$ were expressed as $\mathrm{His}_{6}$ fusion proteins in Escherichia coli, and were purified using $\mathrm{Ni}^{2+}$ and heparin affinity chromatography and gel filtration. Detailed purification procedures are given in the Supplemental Material. Both proteins were complexed with a duplex of the palindromic 22-nt oligonucleotide 5'-CTTTATTCCCA TGGGAATAAAG-3', and were crystallized using the hanging drop vapor diffusion method. Crystals of the Ebf $1^{26-240}$ complex were obtained at $20^{\circ} \mathrm{C}$ in $6 \%(\mathrm{w} / \mathrm{v}$ ) PEG 4000, $100 \mathrm{mM}$ MES (pH 5.7), and $200 \mathrm{mM} \mathrm{KCl} \mathrm{(crystal}$ form I); and $10 \%$ (w/v) PEG 4000 and $200 \mathrm{mM} \mathrm{KCl}$ (crystal form II), whereas crystals of the $\mathrm{Ebf}^{26-422}$ complex grew at $37^{\circ} \mathrm{C}$ in $10 \%$ (w/v) PEG $4000,100 \mathrm{mM} \mathrm{NaCitrate}(\mathrm{pH} 5.4)$, and $10 \%(\mathrm{v} / \mathrm{v})$ isopropanol. X-ray diffraction data of the three crystal forms were obtained at the Swiss Light Source (SLS) and the BESSY, including three-wavelength MAD data of Ebf1 ${ }^{26-240}$ crystal form I soaked with $\mathrm{Ta}_{6} \mathrm{Br}_{14}$ clusters. Statistics of the acquired data sets are given in Supplemental Table S1. Phases were derived from the MAD data using SHARP (de la Fortelle and Bricogne 1997). The other data sets were phased by molecular replacement using CCP4 PHASER (McCoy et al. 2007) and the structure model of the Ebf1 DBD:DNA complex derived from crystal form I.

\section{Refinement}

Model building was performed in COOT (Emsley and Cowtan 2004), and refinement was carried out using CCP4 Refmac5 (Murshudov et al. 1997). The individual protein domains were defined as TLS groups in the refinement process. For structure validation, MolProbity (Davis et al. 2007) was employed. Refinement statistics are given in Supplemental Table S2. Superpositions of structures were done with LSQMAN (Kleywegt 1996), and interfaces, given as one-half BASA, were analyzed using PISA (Krissinel and Henrick 2007). Figures of the structure models were created using MOLSCRIPT (Kraulis 1991) and rendered with POVRAY (http:// www.povray.org). Additional methods can be found in Supplemental Material.

\section{Database entries}

The coordinates of the presented structures were deposited in the Protein Data Bank (http://www.pdb.org) under accession codes 3MLN, 3MLO, and 3MLP.

\section{Acknowledgments}

We thank the staff at the SLS and BESSY synchrotrons for assistance during data acquisition. We thank P. Cramer for advice in the design of oligonucleotides, and K.P. Hopfner for discussions and comments on the manuscript. The initial crystallization and X-ray analysis of Ebf $1^{26-422}$ were carried out in the laboratory of G.E. Schulz at the University of Freiburg, Germany. This work was supported by funds of the Max-Planck Society and German Research Foundation. 


\section{References}

Davis IW, Leaver-Fay A, Chen VB, Block JN, Kapral GJ, Wang X, Murray LW, Arendall WB III, Snoeyink J, Richardson JS, et al. 2007. MolProbity: All-atom contacts and structure validation for proteins and nucleic acids. Nucleic Acids Res 35: W375-W383. doi: 10.1093/nar/ gkm216.

de la Fortelle E, Bricogne G. 1997. Maximum-likelihood heavy-atom parameter refinement for the multiple isomorphous replacement and multiwavelength anomalous diffraction methods. Methods Enzymol 276: 472-494.

Emsley P, Cowtan K. 2004. Coot: Model-building tools for molecular graphics. Acta Crystallogr D Biol Crystallogr 60: 2126-2132.

Garel S, Marin F, Grosschedl R, Charnay P. 1999. Ebf1 controls early cell differentiation in the embryonic striatum. Development 126: 5285-5294.

Ghosh G, van Duyne G, Ghosh S, Sigler PB. 1995. Structure of NF-кB p50 homodimer bound to а кB site. Nature 373: 303-310.

Giffin MJ, Stroud JC, Bates DL, von Koenig KD, Hardin J, Chen L. 2003. Structure of NFAT1 bound as a dimer to the HIV-1 LTR $\kappa$ B element. Nat Struct Biol 10: 800-806.

Hagman I, Travis A, Grosschedl R. 1991. A novel lineage-specific nuclear factor regulates mb-1 gene transcription at the early stages of $\mathrm{B}$ cell differentiation. EMBO I 10: 3409-3417.

Hagman J, Gutch MJ, Lin H, Grosschedl R. 1995. EBF contains a novel zinc coordination motif and multiple dimerization and transcriptional activation domains. $E M B O J$ 14: 2907-2916.

Holm L, Kaariainen S, Rosenstrom P, Schenkel A. 2008. Searching protein structure databases with DaliLite v.3. Bioinformatics 24: 2780-2781.

Jimenez MA, Akerblad P, Sigvardsson M, Rosen ED. 2007. Critical role for Ebf1 and Ebf2 in the adipogenic transcriptional cascade. Mol Cell Biol 27: 743-757.

Kim K, Colosimo ME, Yeung H, Sengupta P. 2005. The UNC-3 Olf/EBF protein represses alternate neuronal programs to specify chemosensory neuron identity. Dev Biol 286: 136-148.

Kleywegt GJ. 1996. Use of non-crystallographic symmetry in protein structure refinement. Acta Crystallogr D Biol Crystallogr 52: 842-857.

Kraulis PJ. 1991. MOLSCRIPT: A progam to produce both detailed and schematic plots of protein structures. J Appl Crystallogr 24: 946-950.

Krissinel E, Henrick K. 2007. Inference of macromolecular assemblies from crystalline state. J Mol Biol 372: 774-797.

Krzemien I, Dubois L, Makki R, Meister M, Vincent A, Crozatier M. 2007. Control of blood cell homeostasis in Drosophila larvae by the posterior signalling centre. Nature 446: 325-328.

Liao D. 2009. Emerging roles of the EBF family of transcription factors in tumour suppression. Mol Cancer Res 7: 1893-1901.

Liberg D, Sigvardsson M, Akerblad P. 2002. The EBF/Olf/Collier family of transcription factors: Regulators of differentiation in cells originating from all three embryonal germ layers. Mol Cell Biol 22: 8389-8397.

Lin H, Grosschedl R. 1995. Failure of B-cell differentiation in mice lacking the transcription factor EBF. Nature 376: 263-267.

Lin YC, Jhunjhunwala S, Benner C, Heinz S, Welinder E, Mansson R, Sigvardsson M, Hagman J, Espinoza CA, Dutkowski J, et al. 2010. A global network of transcription factors, involving E2A, EBF1 and Foxol, that orchestrates B cell fate. Nat Immunol 11: 635-643.

Ma PC, Rould MA, Weintraub H, Pabo CO. 1994. Crystal structure of MyoD bHLH domain-DNA complex: Perspectives on DNA recognition and implications for transcriptional activation. Cell 77: 451-459.

Maier H, Ostraat R, Gao H, Fields S, Shinton SA, Medina KL, Ikawa T, Murre C, Singh H, Hardy RR, et al. 2004. Early B cell factor cooperates with Runxl and mediates epigenetic changes associated with mb-1 transcription. Nat Immunol 5: 1069-1077.

McCoy AJ, Grosse-Kunstleve RW, Adams PD, Winn MD, Storoni LC, Read RJ. 2007. Phaser crystallographic software. J Appl Crystallogr 40: $658-674$

Medina KL, Pongubala JM, Reddy KL, Lancki DW, Dekoter R, Kieslinger M, Grosschedl R, Singh H. 2004. Assembling a gene regulatory network for specification of the B cell fate. Dev Cell 7: 607-617.

Muller CW, Rey FA, Sodeoka M, Verdine GL, Harrison SC. 1995. Structure of the NF-кB p50 homodimer bound to DNA. Nature 373: 311-317.

Murshudov GN, Vagin AA, Dodson EJ. 1997. Refinement of macromolecular structures by the maximum-likelihood method. Acta Crystallogr D Biol Crystallogr 53: 240-255.
Pongubala JM, Northrup DL, Lancki DW, Medina KL, Treiber T, Bertolino E, Thomas M, Grosschedl R, Allman D, Singh H. 2008. Transcription factor EBF restricts alternative lineage options and promotes $\mathrm{B}$ cell fate commitment independently of Pax5. Nat Immunol 9: 203-215.

Sanjabi S, Williams KJ, Saccani S, Zhou L, Hoffmann A, Ghosh G, Gerondakis S, Natoli G, Smale ST. 2005. A c-Rel subdomain responsible for enhanced DNA-binding affinity and selective gene activation. Genes Dev 19: 2138-2151.

Schwabe JW, Klug A. 1994. Zinc mining for protein domains. Nat Struct Biol 1: 345-349.

Siponen MI, Wisniewska M, Lehtio L, Johansson I, Svensson L, Raszewski G, Nilsson L, Sigvardsson M, Berglund H. 2010. Structural determination of functional domains in early B-cell factor (EBF) family of transcription factors reveals similarities to rel DNA binding proteins and a novel dimerisation motif. J Biol Chem 285: 25875-25879.

Stroud JC, Lopez-Rodriguez C, Rao A, Chen L. 2002. Structure of a TonEBP-DNA complex reveals DNA encircled by a transcription factor. Nat Struct Biol 9: 90-94.

Travis A, Hagman J, Hwang L, Grosschedl R. 1993. Purification of earlyB-cell factor and characterization of its DNA-binding specificity. Mol Cell Biol 13: 3392-3400.

Treiber T, Mandel EM, Pott S, Györy I, Firner S, Liu ET, Grosschedl R. 2010. Ebf1 regulates B cell gene networks by activation, repression and transcription-independent poising of chromatin. Immunity 32: 714-725.

Wang SS, Tsai RY, Reed RR. 1997. The characterization of the Olf-1/EBFlike HLH transcription factor family: Implications in olfactory gene regulation and neuronal development. J Neurosci 17: 4149-4158.

Zhang Z, Cotta CV, Stephan RP, deGuzman CG, Klug CA. 2003. Enforced expression of EBF in hematopoietic stem cells restricts lymphopoiesis to the B cell lineage. EMBO I 22: 4759-4769. 


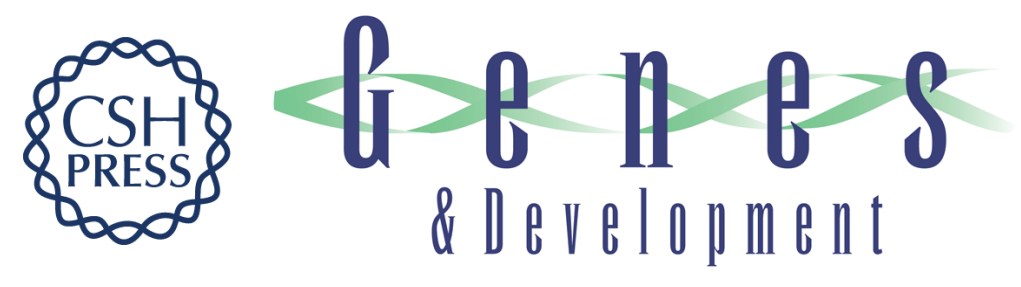

\section{Structure of an Ebf1:DNA complex reveals unusual DNA recognition and structural homology with Rel proteins}

Nora Treiber, Thomas Treiber, Georg Zocher, et al.

Genes Dev. 2010, 24: originally published online September 28, 2010

Access the most recent version at doi:10.1101/gad.1976610

\section{Supplemental http://genesdev.cshlp.org/content/suppl/2010/09/20/gad.1976610.DC1 Material}

References This article cites 34 articles, 9 of which can be accessed free at: http://genesdev.cshlp.org/content/24/20/2270.full.html\#ref-list-1

License Freely available online through the Genes \& Development Open Access option.
Email Alerting Service

